\title{
Role of Agricultural Wastes in Construction Industry
}

\author{
Kumar P R ${ }^{1 *}$, Sreelekshmi K S ${ }^{2}$, Anjana S Babu ${ }^{3}$, Harikrishnan $\mathrm{S}^{4}$, Santhanu G Nath ${ }^{5}$, Leena V P \\ ${ }^{1,6}$ Professor; \\ 2,3,4,5 III yr BTech students \\ Department of Civil Engineering \\ Musaliar College of Engineering \& Technology, Pathanamthitta, Kerala.
}

\begin{abstract}
This technical review paper highlights the research work pertaining to the role of agricultural wastes, such as vegetable fibres, coconut shell, palm oil clinkers, and rice husk ash, in construction industry. Fibres are converted into strands and pulp form. Mainly, it is used in light weight concreting due to its engineering properties. Agricultural wastes are utilized to minimize the environmental pollution as well. It is regarded as an economically viable alternative. Coconut shell is broken and utilized as an aggregate in the construction of flooring tiles. Rice husk ash is utilized as an optimum replacement of cement. In this view it can be concluded that for the replacement of aggregates, rice husk ash, coconut shell and jute fibres can be adopted. This will help to minimize the agricultural wastes and promote environmental sustainability.
\end{abstract}

Keywords- Agricultural wastes; construction industry; environment; engineering properties; sustainability

\section{INTRODUCTION}

It is widely recognized that the use of materials in construction has a large impact on the environment, due to the effects of embodied energy and other environmental impacts, and the problems of disposal of some materials. This applies particularly to non-renewable materials whether they are oil based like plastics or quarried. One option for reducing the impact of construction is to make greater use of materials that are produced from crops, either grown for the purpose or as byproduct of other products. As we all know concrete is a widely used construction material and, huge amount of natural resources are required to make the concrete. Instead of this, for sustainable construction and to reduce the usage of raw material, agricultural waste materials are used. Wide availability of agricultural waste makes them suitable. There is great potential for crops and by-products of animal husbandry to reduce the environmental impact of construction. At the same time construction can help to improve the economic viability of agriculture through adding value to existing crops, using waste agricultural materials or developing new crops. In addition to environmental benefits in production, many of these products bring environmental benefits in use. This relates to better air quality, natural management of moisture levels and reductions in allergic reactions.

Many researchers have conducted works in this area [1][10]. Objective of this review paper is to describe the role of different agricultural wastes used in construction industry viza-viz vegetable fibres, oil palm clinkers, coconut shell and rice husk ash. It is thought that such a study would help to minimize the agricultural wastes and promote environmental sustainability.

\section{BACKGROUND LITERATURE}

\section{A. Vegetable Fibres as non-conventional Building Materials}

Vegetable fibres are widely available in most developing countries. They are suitable reinforcement materials for brittle matrix even though they present relatively poor durability performance. The purpose of fibre reinforcement is to improve the mechanical properties of a given building material, which would be otherwise unstable for practical applications. A major advantage of concerning fibre reinforcement of a brittle material is the composite behaviour after cracking. There are two approaches for the development of new composites in fibre-cement. The first one is based on the production of thin sheets and other non-asbestos components. The later components are similar to asbestos-cement ones and they are produced by well-known industrial-scale processes such as Hatschek and Magnani methods commercially used with high acceptance for building purposes. The second approach consists of producing composites for different types of building components like load-bearing hollowed wall, roofing tiles and ceiling plates, which are not similar to components commercially produced with asbestos-cement [1]. Mechanical properties of some of the fibres is shown in Table I.

TABLE I. MECHANICAL PROPERTIES OF SOME FIBRES

\begin{tabular}{|c|c|c|c|c|c|}
\hline \multirow{2}{*}{ Fibre } & \multicolumn{5}{|c|}{ Properties } \\
\cline { 2 - 6 } & $\begin{array}{c}\text { Densit } \\
\text { (g/cm } \\
\text { ) }\end{array}$ & $\begin{array}{c}\text { Tensile } \\
\text { strength } \\
(\text { Mpa })\end{array}$ & $\begin{array}{c}\text { Modulus } \\
\text { of } \\
\text { elasticity } \\
(\mathbf{G P a})\end{array}$ & $\begin{array}{c}\text { Elongatio } \\
\text { n at } \\
\text { failure } \\
(\%)\end{array}$ & $\begin{array}{c}\text { Water } \\
\text { absorpti } \\
\text { on (\%) }\end{array}$ \\
\hline $\begin{array}{c}\text { Jute } \\
\text { (Corchoru } \\
\text { s } \\
\text { capsularis } \\
\text { (\%) }\end{array}$ & 1.36 & $400-500$ & 17.4 & 1.1 & 250 \\
\hline $\begin{array}{c}\text { Coir } \\
\text { (Cocos } \\
\text { nucifera) }\end{array}$ & 1.17 & $95-118$ & 2.8 & $15-51$ & 93.8 \\
\hline $\begin{array}{c}\text { Banana } \\
\text { (Musa } \\
\text { cavendish } \\
\text { ii) }\end{array}$ & 1.30 & $110-130$ & 0.02 & $1.8-3.5$ & 400 \\
\hline $\begin{array}{c}\text { Bamboo } \\
\text { (Bambusa } \\
\text { vulgaris) }\end{array}$ & 1.16 & 575 & 28.8 & 3.2 & 145 \\
\hline
\end{tabular}

In order to improve the durability of the composites, diminution of the matrix alkalinity was attempted. The main component to produce the paste matrix was the alkaline granulated iron blast-furnace slag (BFS) ground to $500 \mathrm{~kg} / \mathrm{m}^{2} / 1$ Blaine fineness, presenting the following oxide composition: $\mathrm{SiO}_{2}-33.78 \%, \mathrm{Al}_{2} \mathrm{O}_{3}-13.11 \%, \mathrm{Fe}_{2} \mathrm{O}_{3}-0.51 \%, \mathrm{CaO}-42.47 \%$, 
$\mathrm{MgO}-7.46 \%, \mathrm{SO}_{3}-0.15 \%, \mathrm{Na}_{2} \mathrm{O}-0.16 \%, \mathrm{~K}_{2} \mathrm{O}-0.32 \%$, free $\mathrm{CaO}-0.10 \%$, and $\mathrm{CO}_{2}-1.18 \%$. GBFS costs can be as low as USD 10.00 per ton. For the cement production, slag must be ground to fineness at least similar to that of the ordinary Portland cement, which adds a further cost of approximately USD 15.00 per ton, and it must be activated by alkaline compounds. Gypsum for agricultural purposes and lime (calcium hydroxide) for civil construction were elected as chemical alkali-activators for BFS respectively in proportions of $10 \%$ and $2 \%$ (binder mass basis),as Standard commercial ordinary Portland cement (OPC), Adelaide Brighton brand type "general purpose" (GP), minimum compressive strength of 40 $\mathrm{MPa}$ at 28 days (Australian Standards AS 3972 and AS 2350.11) was adopted as the reference matrix to compare with BFS cement. Figure 1 presents the effect of the fiber content respectively on mechanical and physical performance of composites. All BFS composites showed a considerable increase (at least 20\%) in flexural strength within the 8-12\% fiber content interval if compared to the corresponding $4 \%$ fiber content composites. The short length of Eucalyptus grandis allowed the inclusion of up to $16 \%$ of fiber by binder mass although losing flexural strength, which could be associated to the high volume of permeable voids. As Eucalyptus grandis fiber content increased from $4 \%$ to $16 \%$, the elastic modulus in bending of BFS composites decreased from $9 \mathrm{GPa}$ to $4 \mathrm{GPa}$, a behavior that was equally observed for the other similar fiber-cements. Materials with $8 \%$ fiber OPC showed significantly higher modulus than corresponding BFS ones, likely due to insufficient hydration attributed to the BFS binder as previously commented.

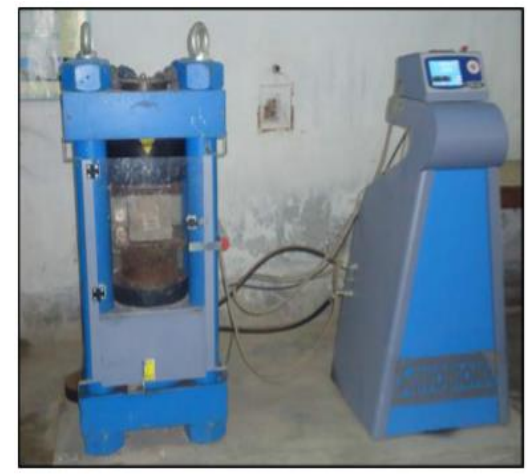

Fig. 1. Compression testing machine

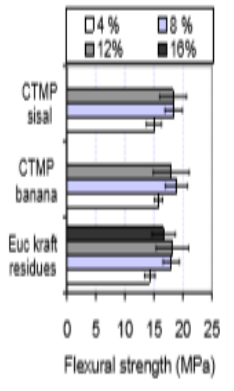

(a)

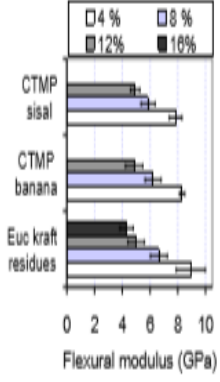

(b)

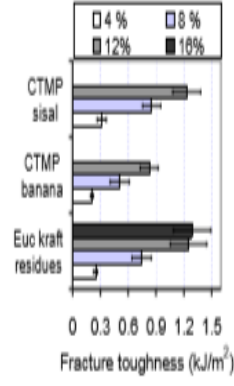

(c)
Fig. 2. Variation of mechanical properties as a function of fiber content (\% mass basis) for composites with different pulp fibers [1]

\section{B. Aicultural Waste as Light Weight Aggregate for} Reinforced Concrete

One of the most prominent agriculture industries in Southeast Asia region is the palm oil industry. Countries in the region, especially Malaysia, Indonesia, and Thailand, have vast oil palm plantations. In fact, these countries contributed to a total of close to $90 \%$ of the world's palm oil production in the year 2009. Due to the diverse use of palm oil, there is a huge demand for palm oil around the world. Nevertheless, the increasing amount of palm oil extraction also leads to the large amount of waste materials produced such as oil palm shell (OPS) and palm oil clinker (POC) [2]. OPS is obtained directly by breaking the palm kernel shell which occurs as a byproduct from the palm oil extraction process and is usually dumped in the vicinity of the factories which could lead to land pollution. POC, on the other hand, is obtained through the incineration of palm oil waste in the palm oil mills. Subsequently, the POC was discarded as waste material and this could also lead to deterioration of the surrounding. Besides the palm oil industry, the coconut industry is also a major agriculture field in Southeast Asia countries such as the Philippines and Indonesia. Similar to OPS, coconut shell (CS) is also a waste material produced from the coconut industry. CS is usually discarded as a waste after the coconut is scraped out. Therefore, it also causes environmental concerns due to its insitu dumping [2].

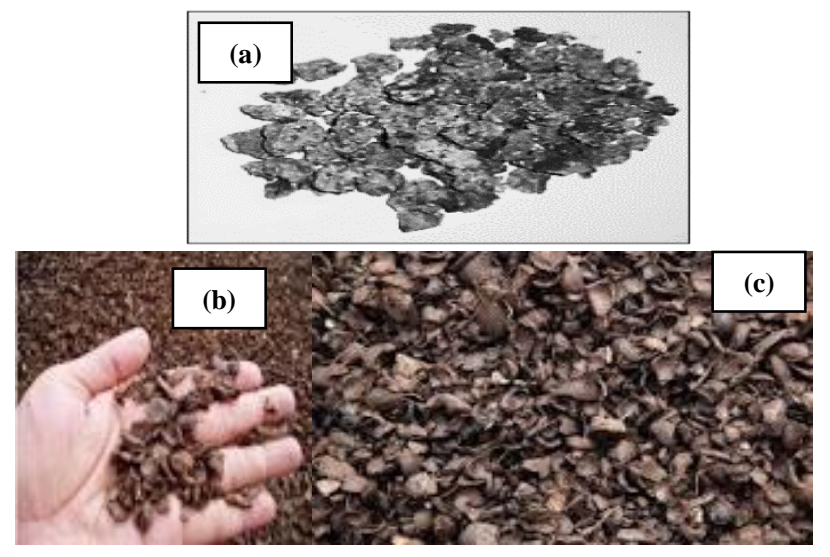

Fig. 3. (a) Oil palm shell, (b) palm oil clinker and (c) coconut shell as lightweight aggregates

In order to establish the structural feasibility and provide a general idea on the performance of such reinforced lightweight concrete member, this paper summarizes the findings obtained in past researches with regard to the structural behaviour of reinforced OPS, POC, and CS concrete members. It is hoped that the information provided in this review will generate interest amongst researchers and practicing engineers into further developing such reinforced lightweight concrete members for future applications in the construction industry.

One of the earliest researches regarding the use of OPS in reinforced concrete was carried out to study the flexural behaviour of the reinforced concrete beam under static loading. In this research, three different tension reinforcement ratios (singly reinforced) were used, namely, $0.46 \%, 0.66 \%$, and $0.98 \%$. It was reported that the beams failed in typical flexural failure mode with steel yielding followed by concrete cover crushing. This suggested that no anomalies were observed despite the use of OPS in the reinforced concrete beam. Interestingly, the experimental ultimate moments were found to 
be $19-35 \%$ higher compared to the predicted moment. This was also observed in a separate study involving the flexural behaviour of singly reinforced OPS concrete beams. Hence, the authors concluded that BS 8110 could be used to give conservative estimate of the moment for reinforced OPS concrete beams. Apart from that, despite the low modulus of elasticity of OPS concrete, the reinforced OPS concrete beam gave acceptable serviceability deflection as the span-deflection ratio ranged between 252 and 263 which fell within the limit (Fig. 4).

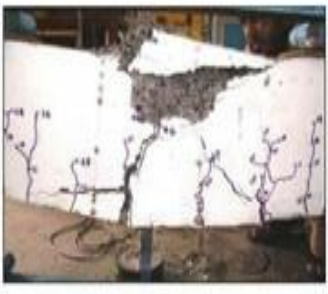

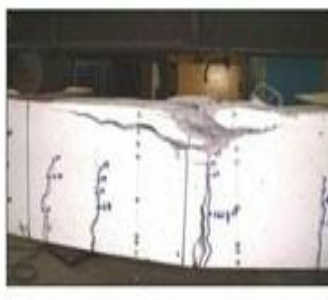

Fig 4. Failure of reinforced, (a) OPS concrete (b) NWC beam

In a more detailed investigation, the flexural behaviour of OPS concrete beams which were singly and doubly reinforced were done. The tension reinforcement ratio used was in the range of $0.46 \%$ to $3.39 \%$. All the beams were found to exhibit typical under reinforced failure despite the increment in the tension reinforcement of up to $3.39 \%$. The difference between the experimental and predicted moments was observed to be between 4 and $35 \%$ and therefore it may be used as the design basis since it gave conservative prediction of the ultimate moment. A difference in the range of $4-21 \%$ was observed between the experimental and predicted serviceability midspan deflections. It was recommended that, for the doubly reinforced OPS concrete beams, larger beam depths should be used to satisfy the span-deflection ratio. When comparing the reinforced OPS concrete beams, the authors observed reduced ductility with the increase in reinforcement ratio. Nevertheless, good ductility was found for the reinforced OPS concrete beams with up to $2.01 \%$ reinforcement ratio since the ductility ratio exceeded 3 . The good ductility behaviour of OPS concrete beams was attributed to the toughness and good shock absorbance provided by the OPS aggregates. Such observation indicates the usefulness of OPS concrete for structural applications since larger deflections could be observed prior to the failure of concrete members and could serve as a warning sign for civilians to escape in case of potential structural member collapse or for early remediation and repairing works to be carried out. In the same investigation, emphasis was also given for the cracking behaviour of the reinforced OPS concrete beams since the cracking behaviour is one of the most important criteria of the serviceability of reinforced concrete members. The crack widths of reinforced OPS concrete beams up to service loads did not exceed the maximum limit of $0.41 \mathrm{~mm}$ stipulated in ACI, such as ACI 318 and BS 8110 both gave reasonable prediction of the serviceability crack widths. This study is of significant importance since it demonstrated that conventional design codes could be safely used in the design for reinforced OPS concrete beams.

\section{Coconut Shell Aggregate in Concrete Flooring Tiles}

The reviewed literature highlighted the research on use of Coconut Shell (CS) in the manufacturing of flooring tiles [3].
The cement used in the manufacturing of flooring tiles was Portland Pozzolana cement in which its properties were confirmed as per IS 12269: 1987. The aggregates used in the wearing layer of tiles were colored stone chips with bulk density of $1850 \mathrm{~kg} / \mathrm{m}^{3}$ and specific gravity 2.7 . Quarry dust was used as a backing layer of the tiles which had the specific gravity of 2.54. Crushed CS was allowed for completely saturated and dried in surface level before it is added to the mixes which were used for moulding in to flooring tiles. Fig 4.1 illustrates the quarry dust, colored stone chips and crushed coconut shells used. Flooring tile size was selected for this study was $300 \times 300 \times 25 \mathrm{~mm}$.

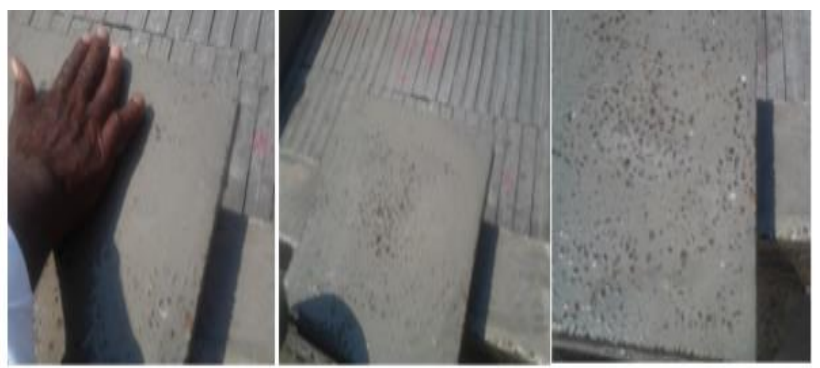

Fig 5.Coconut shell flooring tile

Mix proportion for the production of flooring tiles, the nominal mix proportion 1:3 (by volume) is selected as per IS 1237: 1980. The same volume batched materials generally used in field practice had been adopted in this study. For the traditional flooring tiles, to prepare the base layer people are using a vessel like a mason bond for taking mix constituents. It is reported that to take one part of cement and three part of quarry dust for base layer. It was weighed and converted in to mix ratio by weight as $1: 3.65$ and the water-cement ratio used was 0.40 . The same mix ratio was also adopted in the base layer while producing the coconut shell flooring tiles as well. Similarly, for the traditional flooring tiles, to prepare the wearing layer they used to take one part of cement and three parts of marble chips. It was weighed and converted in to mix ratio by weight was 1: 3.83 and here also the water-cement ratio used was 0.40 . But in case of coconut flooring tiles it was weighed and mix ratio by weight was found to be $1: 3.50$ and here also the water-cement ratio used was 0.40 with the mix ratios adopted [3,4].

\section{Concrete containing Pre-soaked Rice Husk Ash}

The milling of paddy rice (Oryza sativa) produces husk as an agricultural waste with a low nutrition value. The disposal of rice husk has been very difficult globally because of the large ash residue resulting from improper incineration. Nigeria has the potential for ample quality RHA production suitable for use in the construction industry; it is the second largest rice producing country in Africa, and it has been estimated that $748,000-990,000$ metric tonnes of rice husk have been produced based on paddy rice production in 2010 [4,5]. The objective of this study was to determine the effects of presoaked RHA in concrete in terms of slump, compressive strength development, tensile strength and durability properties. By mixing RHA at a low specific surface in equal weight of water, the cellular pores of the RHA are saturated with water and the RHA is in the saturated surface dry 
condition. The extra water should achieve two things in concrete: First, it will reduce the water demand in concrete resulting in lower dose of plasticizer, particularly at high levels of cement replacement. Secondly, this pore water at a microscopic level would be available for hydration as calcium silicate hydrate gels develop in concrete; in this regard, the extent to which this water is available and for how long it is available for hydration should influence the compressive strength development of concrete.

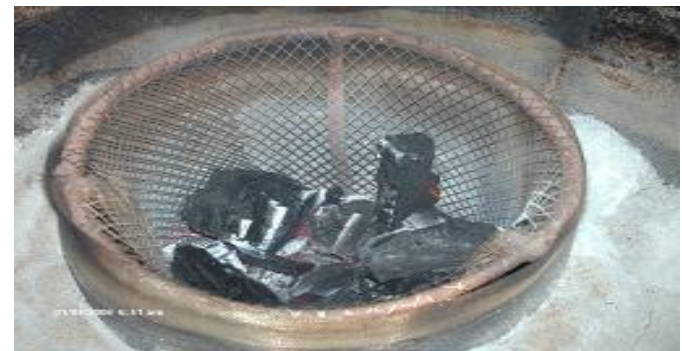

Fig 6. Incinerator converting rice husk into RHA

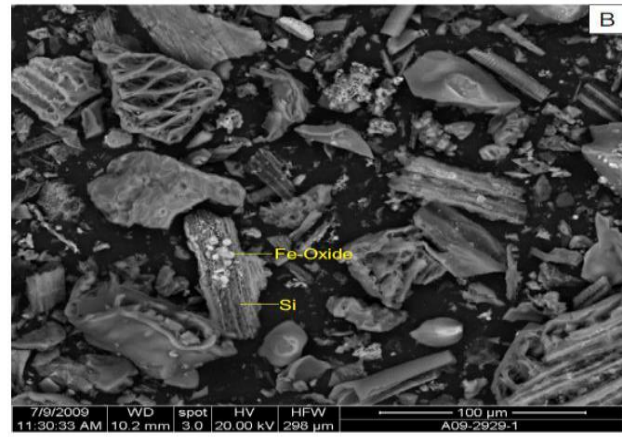

Fig. 7. SEM photo of Cellular microstructure of milled RHA siliceous particles

Weighed RHA was mixed with equal weight of water to produce a soft cake ten minutes before mixing. Half of the weight of coarse aggregates was poured into the rotating mixer; the RHA cake was added and mixed for two minutes before the remaining weight of coarse aggregates was then poured into the mixer. Thereafter, half the weight of the mixing water containing the plasticizer was added to the mixer followed by cement and fine aggregates. The remaining water was then finally added. The concrete mixing in the tilting drum mixer was carried out for three minutes after the final addition of water. The concrete was manually compacted in two layers in $100 \mathrm{~mm}$ steel moulds. The cubes that were designated uncured were removed from the moulds after 24hours and stored in the open air on the laboratory floor. The average daytime temperature recorded was $23^{\circ} \mathrm{C}$ at an average daily relative humidity of $44 \%$. Two sets of cubes were cast for each mix proportion; one set of cubes was continuously cured in water while another set was stored in the open air on the laboratory floor. At predetermined ages, the cubes were removed and their compressive strength was determined.
Since the RHA used was pre-soaked with equal weight of water prior to mixing, the weight of water used for the concrete mix was determined on the basis of cement content only. Concrete cubes without RHA cured in water were used as control. The compressive strength of the cubes $(100 \mathrm{~mm})$ was determined in compliance with BS 1881: part 4:1970 standard using ELE ADR 3000 digital compression machine at a loading rate of $3.00 \mathrm{kN} / \mathrm{s}$; the split tensile strength of concrete cylinders $(150 \mathrm{~mm} \times 300 \mathrm{~mm})$ was determined in compliance with BS 1881: Part 117: 1983 standard using the same machine at a loading rate of $2.10 \mathrm{kN} / \mathrm{s}$. The tensile test results are average of three specimen tests [6]-[10].

\section{CONCLUDING REMARKS}

Following are the concluding remarks drawn from the above review:

1. Coconut shells were more suitable as low strength giving light weight aggregate when used to replace common aggregate in concrete production especially for $\mathrm{M}_{20}$ and $\mathrm{M}_{30}$ grade concrete.

2. Reuse of agricultural waste products leads a sustainable development [1]-[10].

3. Use of agricultural wastes is to improve the mechanical properties of building materials.

4. It has concluded that the usual reduction of slump of fresh concrete associated with the use of RHA in concrete can be drastically reduced by pre-soaking RHA.

5. Extensive research work is required to establish a worldwide environmental sustainable approach to the effective utilization of agricultural waste in construction industry.

\section{REFERENCES}

[1] Agopyan, V.; John, V. M. In: Fibre reinforced cements and concretes: recent developments; Swamy, R. N.; Barr, B.; Eds.; Elsevier: London, UK, 1989; pp. 296- 305.

[2] Agopyan, V.; Savastano Jr., H.; John, V. M.; Cincotto, M. A. Cem. Concr. Compos.2005, 27, 527-536. , V. In: Natural fibre reinforced cement and concrete.

[3] Swamy, R. N.; Ed.;Concrete Technology and Design 5; Blackie: Glasgow, UK, 1988; pp. 208-242.

[4] Savastano Jr., H.; Agopyan, V.; Nolasco, A. M.; Pimentel, L. L. Constr. Build. Mater. 1999, 13, 433-438.

[5] Guimarães, S. S. In: Proceedings of the International Conference Development of LowCost and Energy Saving Construction Materials and Applications; Envo: Rio de Janeiro, Brazil, 1984.

[6] Savastano Jr., H.; Warden, P. G.; Coutts, R. S. P. Cem. Concr. Compos. 2005,27.

[7] Giannasi, F.; Thebaud-Mony, A. Int J. Occup. Environ. Health. 1997, 3, 150-157.

[8] Weigler H, Sieghart K (1980). Structural lightweight aggregate concrete with Reduced density lightweight aggregate foamed concrete. Int J Lightweight Concr. 2(2):101-4.

[9] Elinwa A. U.and Mahmood.Y.A, (2002). Ash from timber waste as cement replacement material. Cem Concr Compo, Vol. 24, p[p.219222.

[10] Mannan MA, Ganapathy C (2002). Engineering properties of concrete with oil palm shell as coarse aggregate. Const Build Mater; $16: 29-34$. 